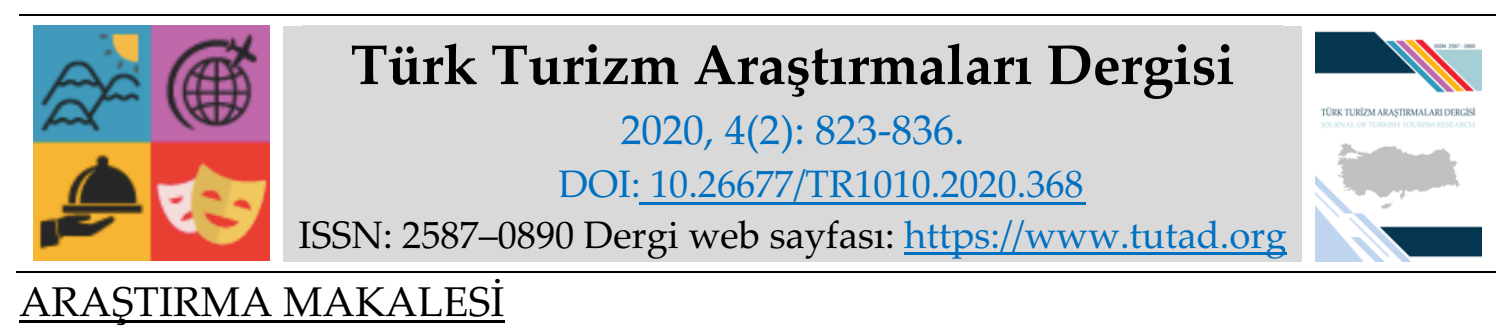

\title{
Rekreasyonel Tema Parkların Ekonomik Etkileri: İsfanbul Tema Park Örneği
}

Ilgın MUTLUBAŞ, Doktora Öğrencisi, Necmettin Erbakan Üniversitesi, Sosyal Bilimler Enstitüsü, Konya, e-posta: ygmrengz@hotmail.com

ORCID: https://orcid.org/0000-0001-8509-8948

Arş. Gör. Dr. Selman BAYRAKCI, Necmettin Erbakan Üniversitesi, Turizm Fakültesi, Konya, eposta: selmanbayrakci@gmail.com

ORCID: https://orcid.org/0000-0003-4012-0907

Doç. Dr. Ceyhun Can ÖZCAN, Necmettin Erbakan Üniversitesi, Turizm Fakültesi, Konya, eposta: ceyhuncan5@hotmail.com

ORCID: https://orcid.org/0000-0002-1951-5894

Öz

Tema park pazarı dünya genelinde son yıllarda giderek büyümektedir. Güçlü müşteri talebi bu büyümeyi beslemektedir. Bu parklar sadece büyüklükleri ve çok sayıda insan ağırlamaları açısından değil aynı zamanda ekonomik ve sosyal etkileri nedeniyle de turizmin bir parçası haline gelmişlerdir. Tema parklar yalnızca kuruldukları ülkenin ekonomisine değil aynı zamanda o bölgede yaşayan insanların ekonomik durumlarına da etki etmektedir. Bu araştırmada da amaç, İsfanbul Tema parkının bölgede yaşayan insanların ekonomik gelirlerine etkisini belirlemektir. İstanbul'da hizmet sunan İsfanbul Tema Parkının ekonomik etkilerin belirleyeme yönelik hazırlanan bu çalışma, nicel araştırma yaklaşımı ile hazırlanmıştır. Veriler anket yöntemi uygulanarak elde edilmiştir. Elde edilen sonuçlara göre ise; bağımsız değişkenlerden "Sosyo-Kültürel", "Kalabalık ve Yoğunluk", "Çevresel", "Hizmetler" ve "Vergiler" değişkenlerinin yöre sakinlerin ekonomik getirisine etki ettiği, "Yöre Sakinlerinin Tutumu" değişkeninin ise anlamlı bir etkiye sahip olmadığı görülmüştür. Bu çalışmada bölgesel gelişme ve destinasyonların sürdürülebilirliği açısından politika yapıcıların tema parkların rasyonel kurgulanıp ve yönetilmesine daha çok önem vermesi gerektiği öneri olarak sunulmuştur.

Anahtar Kelimeler: Tema parklar, İsfanbul Tema Parkı, Ekonomik Etki.

Makale Gönderme Tarihi: 20.01.2020

Makale Kabul Tarihi: 14.04 .2020

\section{Önerilen Atıf:}

Mutlubaş, I., Bayrakcı, S. ve Özcan, C. C. (2020). Rekreasyonel Tema Parkların Ekonomik Etkileri: İsfanbul Tema Park Örneği, Türk Turizm Araştırmaları Dergisi, 4(2): 823-836.

(C) 2020 Türk Turizm Araştırmaları Dergisi. 


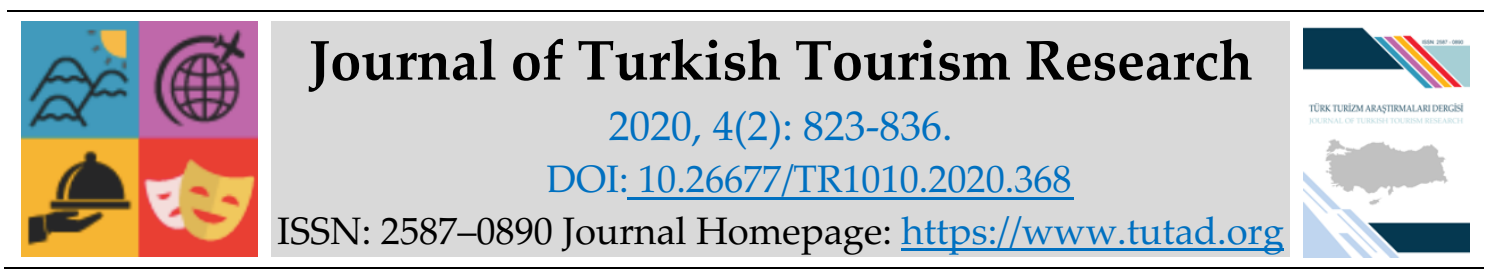

RESEARCH PAPER

\title{
Economic Effects of Recreational Theme Parks: The Case of İsfanbul Theme Park
}

Ilgın MUTLUBAŞ, Ph.D. Student, Necmettin Erbakan University, Social Sciences Institute, Konya, e-mail: ygmrcngz@hotmail.com

ORCID: https://orcid.org/0000-0001-8509-8948

Dr. Selman BAYRAKCI, Necmettin Erbakan University, Faculty of Tourism, Konya, e-mail: selmanbayrakci@gmail.com

ORCID: https://orcid.org/0000-0003-4012-0907

Associate Prof. Dr. Ceyhun Can ÖZCAN, Necmettin Erbakan University, Faculty of Tourism, Konya, e-mail: ceyhuncan5@hotmail.com

ORCID: https://orcid.org/0000-0002-1951-5894

\begin{abstract}
The theme park market is growing steadily in recent years the worldwide. Strong customer demand nurtures this growth. These parks have become a part of tourism not only because of their size and the large number of people they entertain, but also because of their economic and social impact. Theme parks affect not only the economy of the country in which they are established, but also the economic conditions of the people living in that region. The aim of this study is to determine the effect of İsfanbul Theme Park on the economic income of the people living in the region. This study, which was prepared to determine the economic impacts of İsfanbul Theme Park in İstanbul, was prepared with a quantitative research approach. The data were obtained by using questionnaire method. According to the results obtained; Although "Socio-Cultural", "Crowded" and "Density", "Environmental", "Services" and "Taxes", which are independent variables, affect the economic return of local residents, "Attitude of the Residents" had no significant effect. In this study, it is suggested that policy makers should give more importance to the rational design and management of theme parks in terms of regional development and sustainability of destinations.
\end{abstract}

Keywords: Theme parks, İsfanbul Theme Parks, Economics Impact.

Received: 20.01.2020

Accepted: 14.04 .2020

\section{Suggested Citation:}

Mutlubaş, I., Bayrakcı, S. and Özcan, C. C. (2020). Economic Effects of Recreational Theme Parks: The Case of İsfanbul Theme Park, Journal of Turkish Tourism Research, 4(2): 823-836.

(c) 2020 Türk Turizm Araştırmaları Dergisi. 


\section{Gíriş}

Tema parklar, rekreasyonel bir faaliyet alanı olarak belirli bir ilgi alanına yönelik olmak üzere geniş bir yüzeye yayılmış eğlence yerleri olarak kabul görmektedir. Genelde her yaş aralığına ve insanların kitlesel olarak eğlenmelerine aracılık eden tema parklarda belli bölgelerinde belirli yaş gruplarına yönelik etkinlikler de düzenlenebilmektedir. Tema parkları lunaparklardan ayıran en temel özellik, eğlence parklarında da bulunan yüksek hızlı adrenalin treni (roller coaster), eğlence sürüşleri (ride), dönme dolap gibi eğlence sistemlerinin bir kurgu çerçevesinde öyküler ile birleştirip, ziyaretçilerine konsept olarak sunmalarıdır (Bobat, 2016). Dolayısıyla tema parklar, ziyaretçilere eğlence ve yeni deneyimler sunmak amacıyla geliştirilmiş rekreasyonel bir faaliyettir. Bu parkların kuruluşunun ekonomiye önemli katkısı vardır ve ortaya çıkışı turizm üzerinde oldukça etkili olmuştur. Bu etki ise turizmde yeni trendler oluşturmuştur. Tema parklar, yıllar boyunca çok yüksek sayılarda misafir ağırladıklarından dolayı toplam küresel turizmin önemli bir bölümünü oluşturmaktadır (www.tourismembassy.com). Örneğin, Walt Disney Orta Florida'da yeni bir tema parkı inşa edileceği açılandığında, piyasanın ana konusu turizm gelişimi olmuştur ve yılda 13-15 milyon turist çekmiştir (Sun ve Uysal, 1994: 74).

Tema parklar, yerel topluluklara hitap etmesinin yanı sıra turistler için de eğlence ve rekreasyon alanı sağladığı için hükümetler, genellikle tema parkların geliştirilmesini desteklemektedir ve girişimcilere teşvik sağlamaktadır. Bu parklar yerel olarak, ulusal olarak ve bazen de uluslararası alanda siyasi avantaj elde etmek için fırsatlar sunabilmektedir. Büyük şirketler; kar, ürün portföyünün çeşitlendirilmesi, yatırım getirisinin belirli bir orana ulaşması ve şirketin pazar payının arttırılması nedeniyle tema parklara ve turistik yerlere yatırım yapmaktadırlar. Kurulan yeni parklar destinasyonun imajını iyileştirebilir, turizmi arttırabilir ve dolayısıyla yerel halk için ekonomik fayda sağlayabilmektedir. Ayrıca işgücü piyasasının tüm kesimlerinde istihdam olanağı sağlayarak hedefin sürdürülebilirliğine katkıda bulunabilmektedir (Okumus ve Dickson, 2010: 339). Dolayısıyla turizm, sermaye harcamaları üzerinde önemli bir azaltıcı etkiye sahiptir. Çünkü turizmi desteklemek, gerekli alt yapıyı oluşturmak ve sürdürebilmek için yapılan büyük sermaye harcamalarına ihtiyaç vardır. Park ve rekreasyon harcamaları da turizmden etkilenmektedir. Turistin para harcaması, ülkelere ekonomik katkı sağlayan bir ihracat olarak görülmektedir. Bir "taze" dolar ekonomiye girdiğinde çarpan mekanizması ekonomiyi çeşitli şekilde etkilemektedir. Doların ekonomide kalmış kısmı tasarruf edilebilir, ödünç verilebilir, harcama, yatırım veya alımlar için kullanılabilir (Braun, 2000: 5-7).

\section{KURAMSAL ÇERÇEVE}

Tema park, tarihi geçmişe kadar uzanan üç farklı gelenekten doğmuştur. Bunlardan en eski olanı kökeni Orta Çağa kadar dayanan ve 1133 yılında İngiltere' de başlayan Bartholomew Fuarıdır. 18 ve 19. yüzyıla kadar bu gibi yerler halkın cadı gösterileri, akrobatlık, hokkabazlık gibi kitlesel olarak görebilecekleri ve eğlenmelerine aracılık eden parklardan türemiştir. Dünyanın en eski eğlence parkı olarak kabul edilen park ise Danimarka'nın başkenti Kopenhang kuzeyindeki Klampenborg'da 1583 yılında açılmıştır (Bobat, 2016). 1800'lerin sonunda, endüstrinin Amerika kentlerinde baskın olması ile eğlence parklarına da yer verilmeye başlanmıştır. 1893'te Chicago'da açılan "World's Columbian Exhibition" sonraki örnekler için başlangıç kabul edilmektedir. Fuarda zamanla yabancı ziyaretçi ve sanatçıların yer aldığ 1 çeşitli gösteriler ve etkinliklere de düzenlenmiştir. Daha sonra Newyork Coney Islanad' da yer alan eğlence parkı, su içi ve çeşitli rekreasyonel aktivitelere olanak sağlaması ve çok sayıda yapısal elemanı ile eğlence temalı parkların öncüsü olmuştur (Arslan, 2016). 
1950 yılına gelindiğinde eğlence parklarının çoğu terk edilmiş duruma gelmiş ve mali yönden güçlük çekmeye başlamışlardır. 1955 yılında Walt Disney'in California'da Disneyland'1 açmasıyla birlikte tema park endüstrisi yeniden canlanmıştır. Bu parkın başarılı olmasındaki nedenlerden bazıları, her yaş kesimi için temaları olması ve çok temalı konseptte öncü olmalarıdır. Disney'in satışları 1984 yılında 1,46 milyar dolarken 1989 yılında 4,59 milyar dolara yükselmiştir. Şirketin piyasa değeri ise 1984 yılında 2 milyar dolarken 1988'de 16 milyar dolara ulaşmış ve \%700'lük bir artış yaşanmıştır. Disney'in bu başarısı, ABD genelinde diğer tema parkların kurulmasına öncülük etmiştir (Sun ve Uysal, 1994: 71). 2016 yılında yayınlanan Theme Index raporuna göre dünya genelinde tema parkı katılım büyümelerinde olumlu performans devam etmiş ve toplam iş hacmi \%4,3'lük artışla 420 milyar dolar, yıllık katılımcı sayısı ise 438 milyona ulaşmıştır. Örnek olarak sadece Amerika Birleşik Devletleri'nde, eğlence ve tema parklarından elde edilen gelirin 2019 yılında 22 milyar ABD dolarının üzerinde olduğu tahmin ediliyor ve bunun gelecekte de artmaya devam etmesi beklenmektedir (www.statista.com).

Tema parkların zaman içindeki gelişimi her ülkede farklılık göstermiştir. Bu farklılıklar ekonomik gelişme seviyesi ve zenginliğin dağılımı, ulaşım sistemi, doğal çevre ve inşa edilmiş miras, ulusal kültür, turizmin gelme derecesi ve iç talepten ziyade yabancı ziyaretçiler gibi faktörlerden kaynaklanmaktadır (Raluca ve Gina, 2008: 636). Tablo 1'de görüldüğü üzere, ABD'de ve Kanada'da piyasanın olgunluğu, birkaç girişimcinin elindeki çok sayıda parkın yoğunlaşmasını ve ana şirketler arasında çeşitlendirme ve uluslararası genişleme stratejilerinin yükselmesini sağlamıştır. Piyasa olgunluğunun henüz gerçekleşmediği Avrupa'da ise halkın tekilliği (yerleşim sisteminin dağılımı), sosyal tekillik (tüketim kalıpları) ve ekonomik tekillik (gelir dağılımındaki farklılıklar) ile bağlantılı olan tema parkları sisteminin yeniden düzenlenmesi ve yeniden konumlandırılması dinamiği bulunmaktadır. Bununla birlikte, Asya / Pasifik'te yalnızca belirli alanların ve belirli park biçimlerinin katıldığı yoğun bir genişleme süreci üretilmektedir (Clavé, 2007: 49).

Tablo 1. Dünyada Bölgelere Göre Tema Parkı Gelişim Dinamiği

\begin{tabular}{|l|l|l|l|l|}
\hline & $\begin{array}{l}\text { Amerika- } \\
\text { Kanada }\end{array}$ & Avrupa & Asya/Pasifik & Dünyanın Geri Kalanı \\
\hline $\mathbf{1 9 5 0}$ & Başlama & & & \\
\hline $\mathbf{1 9 6 0}$ & Gelişme & Başla & & \\
\hline $\mathbf{1 9 7 0}$ & Genişleme & Gelişme & Başlama & \\
\hline $\mathbf{1 9 8 0}$ & Olgunluk & Genişleme & Gelişme & Başlama \\
\hline $\mathbf{1 9 9 0}$ & Konsantrasyon & Adaptasyon & Genişleme & Gelişme \\
\hline $\mathbf{2 0 0 0}$ & Çeşitlendirme & Yeniden & Seçici Büyüme & Genişleme \\
\hline
\end{tabular}

Kaynak: (Clavé, 2007: 49)

Themed Entertainment Association (TEA) her yıl dünya çapında tema parklarının bir önceki yılda gösterdiği performans, ziyaretçi sayılarının belirtildiği "Theme Index" adlı rapor yayımlanmaktadır. TEA (2018) raporuna göre, temalı eğlence sektörü 2018 yılında \%5,4 oranında büyüme kaydetmiştir. Bu büyümeye karşın dünyadaki en büyük 25 tema parkının büyüme oranının $\% 3,3$ oranına gerilediği görülüyor. 
Tablo 2. Dünyadaki En Büyük 10 Tema Park Sıralaması

TEMA PARKLAR

\begin{tabular}{|c|c|c|c|c|c|}
\hline & & 2015 & 2016 & 2017 & 2018 \\
\hline 1 & $\begin{array}{l}\text { Magic Kingdom at Walt Disney } \\
\text { World, Us. }\end{array}$ & $20,492,000$ & $20,395,000$ & $20,450,000$ & $20,859,000$ \\
\hline 2 & Disneyland, Anaheim, Us. & $18,278,000$ & $17,943,000$ & $18,300,000$ & $18,666,000$ \\
\hline 3 & Tokyo Disneyland, Tokyo, Japan. & $16,600,000$ & $16,540,000$ & $16,600,000$ & $17,907,000$ \\
\hline 4 & $\begin{array}{l}\text { Universal Studios Japan, Osaka, } \\
\text { Japan. }\end{array}$ & $13,900,000$ & $14,500,000$ & $14,935,000$ & $14,300,000$ \\
\hline 5 & Tokyo Disney Sea, Tokyo, Japan. & $13,600,000$ & $13,460,000$ & $13,500,000$ & $14,651,000$ \\
\hline 6 & Epcot at Walt Disney World, Fl, Us. & $11,798,000$ & $11,712,000$ & $12,200,000$ & $12,444,000$ \\
\hline 7 & $\begin{array}{l}\text { Disney's Animal Kingdom at Walt } \\
\text { Disney World, Us. }\end{array}$ & $10,922,000$ & $10,844,000$ & $12,500,000$ & $13,750,000$ \\
\hline 8 & $\begin{array}{l}\text { Disney's Hollywood Studios at Walt } \\
\text { Disneyworld, Us. }\end{array}$ & $9,585,000$ & $10,776,000$ & $10,722,000$ & $11,258,000$ \\
\hline 9 & $\begin{array}{l}\text { Universal Studios at Universal } \\
\text { Orlando, Us. }\end{array}$ & $8,792,000$ & $9,998,000$ & $10,198,000$ & $10,708,000$ \\
\hline 10 & $\begin{array}{l}\text { Islands of Adventure at Universal } \\
\text { Orlando, Us. }\end{array}$ & $9,383,000$ & $9,362,000$ & $9,549,000$ & $9,788,000$ \\
\hline
\end{tabular}

Kaynak: (Themed Entertainment Association, 2018: 10).

Raluca ve Gina (2008), artan tema parkı sayısı göz önüne alındığında bu rekabetçi pazarda hayatta kalmak için gelecekteki tüketici davranış eğilimi ve artan sayıdaki tema parkların optimize edilmesi gerektiği sonucuna varılabileceğini belirtmişlerdir. Bir diğer araştırmacı De Groote (2011) SWOT analizi ile yapmış olduğu çalışmada, Disney Company'nin güçlü ve zayıf yanlarını ortaya koymuştur. Güçlü yanlarını; eğlence sektöründeki deneyim (80 yılı aşkın), turistik çekim, güçlü itibar ve marka adı, geniş şirket ürün yelpazesi-farklı cazibe alanları ve ürünler, Disney'in ilgi çekici mekânları-ziyaretçi tercihlerinde değişiklik, tanıdıklık, mali istikrar ve kalifiye ve eğitimli çalışanlar olarak sıralarken, zayıf yanlarını; büyük iş gücü, üst düzey yönetim, yüksek işletim maliyetleri, farklı kültür, biletler için yüksek fiyat, tasarım duplikasyonu, kültürel emperyalizm, ziyaretçi harcamaları olarak sıralamışlardır.

Arroyo (2007) ise araştırmasında, ziyaretçi harcamalarının ve Costa Daurada'daki tema parkın istihdam yaratmadaki etkisinin ekonomiye olumlu yansıdığını ancak bölgede yerel ekonomideki sızıntılar gibi bazı olumsuz ekonomik etkilere de neden olduğunu belirtmiştir. Tema parkların çevresinde park, yiyecek, hediyeler ve diğer hizmet ücretlerinden gelir ve karlar elde edilebilmektedir. Bu nedenle, turizm ve otelcilik firmalarının yenilikçi bir şekilde değer yaratan deneyimler tasarlaması, pazarlaması ve sunması gerekmektedir (Geissler ve Rucks, 2011: 128). Tema parklar, turizm endüstrisinin çeşitli yönleri tarafından topluca desteklenip oluşturulan en tipik ticari ürünlerden biridir, dolayısıyla tema parklar ticari rekreasyon ve turizm endüstrisinin ana bileşenlerinin birleştiği alanlarda (seyahat, ağırlama ve rekreasyon alanları vb.) sinıflandırılmakta ve bulunmaktadırlar (Crossley, Jamieson ve Brayley, 2018).

Cengizkan (2014), tema parkı endüstrisinin gelişen trendlerine bakıldığı zaman, tema parkların uluslararası turizm endüstrisinin bir parçası olarak geliştiği yargısına varmaktadır. Uluslararası bakış açısına göre ABD modeli, kör bir şekilde takip edilmeyecek ancak turizmin önemli bir pazar destek kaynağ değerlendiren araştırmacı, Türkiye'nin sadece teknolojik anlamda değil aynı zamanda sosyal ve kültürel olarak kalkınma sürecinden geçtiğini belirtmektedir. Dahası, yaşanan iç ve dış göçler, 
sosyal, kültürel ve davranışsal değişime girdi sağlayan kültürel çeşitlilik yaratmaktadır. Tüm bu faktörler göz önüne alınarak Türkiye ekonomisi, bölgesel ekonomide kalıcı zararlar yaratmadan ve vatandaşların sosyal yaşamında derin kırılmalar yaratmadan bir tema parkın yapımını ve yönetimini destekleyebildiği durumlarda değerlendirilmelidir. Popüler görüşlerin aksine Braun ve Milman (1990), yapılan talep analizi, Central Florida'daki tema parkları arasında yerini alan bir ilişki göstermiştir. Analiz, aynı zamanda bir parkın Disney'e göre ikame edilebilirliğinin derecesinin hem Disney'e hem de niteliklerin sayısına bağlı olarak arttığını göstermiştir.

Yerel yönetimler, tema parkları hızlı turizm gelişimi için bir çare olarak algılayabilirler. Bu nedenle, ekonomik kalkınma ve çevrenin korunmasına neden olacağını umarak büyük miktarda kamu fonunu tema parkına tahsis edebilirler ancak amaçlanan sonuçlar her zaman gerçekleştirilemeyebilir. Örneğin, Kawamura ve Hara (2010), bankaların ve yerel yönetimlerin, Japonya'da vergi ve diğer idari kutsamaları azaltarak tema parklarının inşasını desteklediğine dikkat çekmektedir. Geliştiricilerin ve borçluların bazılarının tema parklar hakkında deneyime sahip olmaması söz konusu desteklerin sonuçlarını riske atmaktadır. Tüm bunlara rağmen Kawamura ve Hara başarılı bir park gelişiminin yerel sürdürülebilirliğe kesinlikle katkıda bulunacağı sonucuna varmışlardır. Buna ek olarak, yerel yönetim ve bölge sakinleri artan vergi gelirleri ve ücret kazanma fırsatları yoluyla tema markasının başarısının dış etkilerinden faydalanacaklardır. Kawamura ve Hara'nın (2010) çalışmasına benzer olarak Henderson (2010) da Singapur'daki iki projeye özel atıfla ziyaretçi cazibe merkezlerinin geliştirilmesi ve sürdürülebilir hedef geliştirmedeki rolleri hakkında ilginç bulgular ve tartışmalar sunmaktadır. Henderson, hükümet yetkililerinin ve yatırımcılarının sürdürülebilir hedef gelişimine katkıda bulunmak için yeni ziyaretçi cazibe merkezleri olarak büyük ölçekli, temalı tesisler tercih edebileceğini önermektedir. Henderson, Singapur'daki hükümetin turizmi şekillendirmede ve şehir devletinin geleceği için bir hedef olarak iddialı vizyonlarının gerçekleştirilmesinde nasıl öncülük ettiğini açıklıyor. Yeni ziyaretçi cazibe merkezlerinin başarısının, bölgesel veya küresel ekonomik ve politik krizler gibi sektör paydaşlarının kontrolünün ötesinde bir dizi faktöre bağlı olduğu sonucuna varıyor. Bu nedenle ticari sonuçlar hayal kırıklığı yaratabilir ve resmi kalkınma stratejilerinin etkinliği zayıflayabilir. İyi çalışma ilişkilerinin oluşturulması, yasal ve düzenleyici çerçevelere saygı gösterilmesi için uluslararası sınırları aşabilecek kamu ve özel alanların içinde ve arasında ortaklıklar gerekebilir. Henderson, yeni tema ve cazibe merkezlerinin olumlu etkilerine ek olarak, tema parkların ve cazibe merkezlerinin potansiyel olumsuz ekonomik, sosyal-kültürel ve ekolojik etkileri konusunu gündeme getirmektedir. Bunlar arasında yerel sakinler için yüksek giriş ücretleri sayılabilir ancak bunlarla sınırlı değildir. Ziyaretçiler ve sakinler, kirlilik, habitat imhası, atık bertaraf problemleri, hava ve gürültü kirliliği ve artan enerji ve su tüketimi seviyeleri gibi nedenle de olumsuz etkilenebilmektedir.

Milman, Okumus ve Dickson (2010) tema parkların ve turistik yerlerin altyapı, iş yaratma, vergi gelirleri, turizm gelirleri, bağışlar ve toplum desteği gibi birçok alanda destinasyonların sürdürülebilirliğine büyük katkı sağladığı sonucuna varmışlardır. Bu durumun aksine Sasaki vd., (1997) tema parkların açılmadan önce sanayi sektöründe inşaat ve hafif elektrik konularında açldıktan sonra ise hizmetler ile ilgili olumsuz etkileri olduğunu tespit etmişlerdir. Bae vd., (2018)'nin yapmış oldukları çalışmada, Disneyland'a yönelik tutumların ve medya tutumlarının Los Angeles'a yönelik tutumları doğrudan etkilediği tespit edilmiştir. Ayrıca tema parkların kent markalaşmasının etkili öncüleri oldukları görülmüştür. Aynı şekilde Levochkina (2018)'e göre, tema parkların başarısı genel olarak ziyaretçilerin güvenliğini ve rahatını sağlamak, temanın özgünlügüne ve güncelliğine, sürekli kendini yenilemesine ve kolay ulaşılabilmesine bağlıdır. Tema park endüstrisi gelişmeye devam etmekte ve bu durumda dinlenme kalitesine, bölgelerin gelişmesine ve yüksek derecede rekabet edilebilirliğe katkı sağlamaktadır. Yeni tema parkları geliştirmek veya mevcut tema parklara yenilerini eklemek büyük sermaye yatırımları 
gerektirmektedir (Milman vd., 2010). Tüm bu yatırımları yaparken hükümetlerin ya da yerel yönetimlerin bölge kapasitesini de dikkate alması oldukça önem arz etmektedir. Turistik destinasyonlara yapılan yatırımlar hem maliyetli hem de zaman alan yatırımlar olmasından dolayı devlet politikaları, bu bölgelerin taşıma kapasitesini ön görmeleri önemlidir. Taşıma kapasitesi kapsamında tema parkları inceleyen Zhang vd., (2017), tema parkı katılımının ziyaretçilerin deneyimini, memnuniyetini ve davranışsal niyetini doğrudan veya dolaylı olarak etkilediğini belirtmişlerdir. Ayrıca araştırmacılara göre tema parkı katılımı, ziyaretçilerin memnuniyet ve davranış niyeti üzerindeki deneyimlerin etkilerini de hafifletmekte ve bunların hepsi bir tema parkının turizm taşıma kapasitesini belirlemekte olduğuna dikkat çekmiştir.

Literatürde ulaşılabilen çalışmalar, birlikte değerlendirildiğinde ekonomik etkiye ya da bölgesel ekonomik etkiye odaklanan çalışmaların oldukça sınırlı olduğu dikkat çekmektedir. Bu açıdan araştırma, literatürde Türkiye ve bölge açısından ekonomik etkiye odaklanması ve ele alması bakımından özgünlük yaratmaktadır.

\section{YÖNTEM}

Tema parkların ekonomik etkisini belirlemeyi amaçlayan bu çalışma, nicel araştırma yaklaşımı ile hazırlanmıştır. Nicel araştırma, sadece gözlem ve betimleme değil, aynı zamanda problemin doğasını açıklama ve onun hakkında tahmin yürütebilme olarak tanımlanmaktadır (Balcı, 2011). Araştırmanın problemini çözmek için izlenecek yol belirlendikten sonra, çalışmanın amacına uygun bir şekilde veri sağlanacak araştırma düzeni (modeli) belirlenmesi gerekmektedir (Karasar, 2005). Bu kapsamda araştırma modellerini ilişki arayan ve ilişki aramayan modeller şeklinde ikiye ayırmak mümkündür. Araştırmada genel tarama modellerinden ilişkisel tarama modeli kullanılmıştır. Çalışma kapsamında detaylı bir alan yazın taraması yapılmış ve bu doğrultuda veri toplama aracı olarak anket formu oluşturulmuştur. Veri toplama aracı iki bölümden oluşmaktadır. Birinci bölümde demografik özellikleri belirlemeye yönelik sorular, ikinci bölümde ise tema parkların ekonomik etkilerini belirlemeye yönelik ifadeler yer almaktadır. İkinci bölümde yer alan "Turizm Etki Ölçeği" Ap ve Crompton (1998) tarafından geliştirilmiştir. Geçerliği ve güvenirliği sağlanmış olan ölçeğin orijinaline bağlı kalınarak araştırmanın amacı doğrultusunda adı geçen ölçek, İsfanbul Tema Parkı için kullanıma hazır hale getirilmiştir. Ap ve Crompton (1998) yaptıkları çalışmada turizm etki ölçeğini 7 boyut (sosyo kültürel, ekonomik, kalabalık ve yoğunluk, çevresel, hizmetler, vergiler, yöre sakinlerinin tutumu) altında incelemiştir. Böylece araştırmacılar, 35 ifadeden oluşan ölçeğin faktör yapısını belirlemişlerdir. Bu çalışmada kullanılan ölçek, Ap ve Crompton (1998) tarafından kullanılan ifade ve boyutlara sadık kalınarak uygulanmıştır.

Araştırma uygulama alanını oluşturan İsfanbul tema parkı, 26 Mayıs 2013'te açılmıştır. 600.000 m2'lik bir alanda hizmet veren İsfanbul, açık ve kapalı alışveriş caddeleri ile farklı bir mimariye sahiptir. 2015 yılında ziyaretçi sayısının yaklaşık olarak 24 milyon olduğu belirtilmiştir. 2016 yılında bu sayı 28 milyon ziyaretçiye ulaşmıştır. Tema park kısmı ziyaretçi sayısı ise 900 bin civarındadır. 2017 yılında ise AVM kısmında 30 milyon, tema park kısminda ise 1 milyon ziyaretçi sayısına ulaşılması beklenmektedir. 


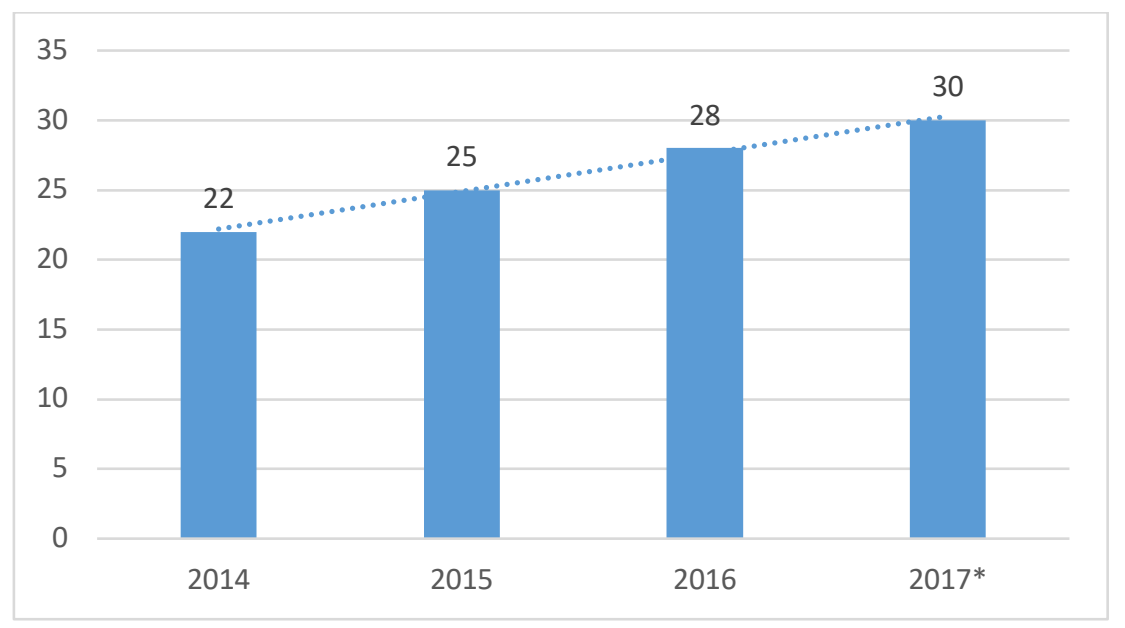

Şekil 1. İsfanbul Toplam Ziyaretçi Sayısı (Milyon kişi)

Kaynak: Yazar tarafından basın bültenlerinden derlenmiştir. *: 2017 yılı tahmindir.

Şekil 1, İsfanbul tema parkının 2014-2017 yılları arasındaki ziyaretçi sayılarını göstermektedir. Burada sunulan rakamlar, AVM ve tema parkın toplam ziyaretçi sayılarının toplamından oluşmaktadır. 2014 yılında 22 milyon iken 2016 yılında ise 28 milyon kişiye ulaşmıştır.

İsfanbul tema parkının ekonomik etkisini belirlemek amacı ile yapılan çalışmanın evrenini, İsfanbul çevresinde yaşayan yerel vatandaşlar oluşturmaktadır. Ancak evrene ulaşmanın zor olduğu durumlarda örnekleme yapmak gerekmektedir. Örneklem hacminin belirlenmesinde "Kabul edilebilir hata düzeyini esas alan yöntem" kullanılmıştır. Ana kütledeki tema parkların ekonomik etkilerine ilişkin oranlar bilinmediği için $p$ ve q değerleri 0,5 alınmış ve mümkün olan en büyük örneklem hacmine ulaşılmıştır. Anketin uygulanacağı birim sayısı, $n=\left\{\mathrm{z}^{2} \mathrm{pq}\right\} / \mathrm{d}^{2}$ formülü yardımıyla hesaplanan denklemde; 0,05 anlamlılık düzeyinde $\mathrm{z}=1,96 ; \mathrm{d}$ (duyarlılık)=0,05 ve $p$ ve $q$ değerleri 0,5 olmak üzere örneklem hacmi 384 olarak hesaplanmıştır (Ural ve Kılıç, 2006). Veri toplama Nisan 2018-Haziran 2018 tarihleri arasında İstanbul'da yaşayan kişilerle online ve yüz yüze görüşülerek yapılmıştır.

Verilerin analiz edilebilmesi için sapan analizi, çoklu normal dağılım testleri ve güvenirlik analizlerinin yapılması uygun görülmüştür. Turizm etki ölçeği için gerçekleştirilen sapan analizinde, 35 madde için \%0.01 anlamlılık düzeyindeki t-testi dağılım tablosundaki kritik değer olan t-değerinin $(2,524,-1,969)$ üstünde 5 adet anket olduğu anlaşılmıştır (Hair, Black, Babin ve Anderson, 2010). Sapma gösteren söz konusu anketler analizden çıkarılmıştır. Gerçekleştirilen sapan analizi sonrasında her iki ölçeğe de çoklu normal dağılım analizi uygulanmıştır. Bu doğrultuda veriye ait skewness (çarpıklık) ve kurtosis (basıklık) değerlerinin hesaplanması, normallikle ilgili bilgiler vermektedir. Özellikle çarpıklık değeri normallikle ilgili son derece yararlı bir parametredir (Yazıcıŏglu ve Erdoğan, 2007). Dolayısıyla çarpıklık ve basıklık değerlerinin $+2,-2$ arasında olması beklenmektedir (George ve Mallery 2010). Bu çalışma için yapılan normallik testleri, çok boyutlu analizlerin yapılabilmesi için bir engel olmadığını göstermektedir. Son olarak turizm etki ölçeğinin güvenirliğini belirlemek için Cronbach'ın Alfa katsayıları dikkate alınmış olup, ölçeğin tamamı için alfa katsayısı ,806 olarak bulgulamıştır. Hair, vd., (2010) yeniden test (Test-Retest) yönteminden sonra en çok başvurulan güvenirlik formlarından birisi olan iç tutarlılık (internal consistency) biriminin, ölçeğin bir bütün halinde tutarlılığını gösterdiğini ve ,70 Cronbach'ın Alfa istatistiğinin alt sınır olduğunu ifade etmektedir. 
Bu sonuçlara göre çalışmada kullanılan örneklem doğrultusunda ölçeğin güvenilir olduğu görülmektedir.

\section{BULGULAR}

Çalışma kapsamında toplanan anketlerden elde edilen veriler, istatistik paket programı yardımı ile bulgulara dönüştürülmüş ve analiz sonuçlarına ulaşılmıştır. Çalışmanın örneklemini oluşturan yerli turistlerin cinsiyet, yaş, meslek, medeni ve eğitim durumlarını gösteren demografik verileri Tablo 3'te yer almaktadır.

Tablo 3. Katılımcıların Demografik Özellikleri

\begin{tabular}{|c|c|c|}
\hline Özellikler & (n) & $(\%)$ \\
\hline \multicolumn{3}{|l|}{ Cinsiyet } \\
\hline Kadın & 209 & 52,6 \\
\hline Erkek & 188 & 47,4 \\
\hline Toplam & 397 & 100 \\
\hline \multicolumn{3}{|l|}{ Yaş } \\
\hline 25 ve alt1 & 49 & 12,3 \\
\hline $26-35$ & 150 & 37,8 \\
\hline $36-45$ & 138 & 34,8 \\
\hline $46-55$ & 42 & 10,6 \\
\hline 55 ve üzeri & 18 & 4,5 \\
\hline Toplam & 397 & 100 \\
\hline \multicolumn{3}{|l|}{ Medeni Durum } \\
\hline Evli & 253 & 63,7 \\
\hline Bekar & 144 & 36,3 \\
\hline Toplam & 397 & 100 \\
\hline \multicolumn{3}{|l|}{ Eğitim Durumu } \\
\hline İlköğretim & 13 & 3,3 \\
\hline Lise & 79 & 19,9 \\
\hline Ön Lisans & 77 & 19,4 \\
\hline Lisans & 189 & 47,6 \\
\hline Lisansüstü & 39 & 9,8 \\
\hline Toplam & 397 & 100 \\
\hline \multicolumn{3}{|l|}{ Meslek } \\
\hline Serbest meslek & 61 & 15,4 \\
\hline Memur (Kamu) & 104 & 26,2 \\
\hline Özel sektör & 110 & 27,7 \\
\hline Öğrenci & 39 & 9,8 \\
\hline İşsiz & 15 & 3,8 \\
\hline Çalışmıyor & 68 & 17,1 \\
\hline Toplam & 397 & 100 \\
\hline
\end{tabular}

Çalışmaya toplam 397 kişi katılmıştır. Bu doğrultuda katılımcıların \%52,6'sını kadınlar, $\% 47,4$ 'ünü ise erkekler oluşturmaktadır. Katılımcıların cinsiyetlerine göre dağılımlarının 
birbirine yakın olmasından dolayı, cinsiyetlerine göre homojen dağılım gösterdiklerini söylemek mümkündür. Katılımcıların yaşlara göre dağılım oranları incelendiğinde ise anketi dolduran katılımcıların, \%12,3'ünü 25 ve altı yaş, \%37,8'ini 26 - 35 yaş, $\% 34,8^{\prime}$ ini $36-45$ ve $\% 15,1^{\prime}$ ini 46 ve üstü yaş grupları oluşturmaktadır. Katılımcıların medeni durumları dikkate alındığında $\% 63,7^{\prime} \operatorname{sinin}$ evli ve \%36,3'ünün bekar olduğu gözlemlenmektedir. Katılımcıların eğitim durumlarını gösteren veriler incelendiğinde $\% 47,66^{\prime} l \mathrm{k}$ oranla lisans düzeyinde eğitimin çoğunlukta olduğu demografik bulgular arasında yer almaktadır. Bu durumu sırasıyla, lise, ön lisans, lisansüstü ve ilköğretim takip etmektedir. Görüldügüü üzere, katılımcıların büyük bir çoğunluğunun eğitim düzeyi yüksek kişilerden oluşturmaktadır.

Katılımcların büyük bir çoğunluğu (\%45,3) 11 ve üzeri yıldır İsfanbul Tema Parkı çevresinde ikamet etmektedir. Sonuç olarak çalışmaya katılan bireylerin önemli bir çoğunluğu 5 ve üzeri yıldır bu bölgede ikamet etmektedir. Detaylı veriler, Tablo 4' de verilmektedir.

Tablo 4. Katılımcıların İkamet Süresi

\begin{tabular}{|l|c|c|}
\hline İkamet Süresi & (n) & (\%) \\
\hline 1 yll & 20 & 5,0 \\
\hline $2-3$ y1l & 34 & 8,6 \\
\hline $4-5$ y1l & 70 & 17,6 \\
\hline $6-10$ y1l & 93 & 23,4 \\
\hline 11 ve üzeri yıl & 180 & 45,3 \\
\hline Toplam & $\mathbf{3 9 7}$ & $\mathbf{1 0 0}$ \\
\hline
\end{tabular}

Turizm etki ölçeğinin boyutlarının (Sosyo Kültürel, Kalabalık ve Yoğunluk, Çevresel, Hizmetler, Vergiler, Yöre Sakinlerinin Tutumu), ekonomi üzerine etkisini belirleyen regresyon analizi bulguları Tablo 5'de gösterilmektedir. Söz konusu analizde '1. Sosyo kültürel düzeydeki gelişmeler, ekonomik gelişmeyi etkiler mi?', '2. Kalabalık ve Yoğunluktaki gelişmeler, ekonomik gelişmeyi etkiler mi?', '3. Çevre üzerindeki gelişmeler, ekonomik getiriyi etkiler mi?', '4. Hizmetlerde yaşanan gelişmeler, ekonomik getiriyi etkiler mi?', ‘5. Vergilerde yaşanan değişim, ekonomik gelişmeyi etkiler mi?', '6. Yöre sakinlerinin tutumundaki değişimler, ekonomik getiriyi etkiler mi?’ sorularına yanıt aranmaktadır.

Turizm etki modelinde yer alan boyutların, yöre sakinlerinin ekonomik düzeyine etkisi üzerine oluşturulan modelin anlamlı olduğu tespit edilmiştir $(\mathrm{p} \leq, 000)$. Bu kapsamda, turizm etki ölçeğinde yer alan boyutların, yöre sakinlerin ekonomik düzeyinin \%56'sını açıklamaktadır $(p \leq, 000)$. Bir bütün halinde geçerli olduğu anlaşılan modelin çoklu bağlantı istatistikleri incelendiğinde oto-korelasyon (D-W Testi: 1,748) ve çoklu bağlantı sorunları (Tolerans: 0,566 0,763 ve VIF:1,310 - 1,766 aralıklarında) yaşanmadığı anlaşılmaktadır. D-W istatistiğinin 1,5-2,5 aralığında olması (Küçüksille, 2010), tolerans değerinin 0,200'den daha küçük olmaması (Büyüköztürk 2009), VIF değerlerinin 10'dan (Alpar, 2010) ve CI değerlerinin de 30'dan büyük olmaması (Büyüköztürk, 2009) oto-korelasyon ve çoklu bağlantı olmaması açısından beklenen değer aralıklarıdır. 
Tablo 5. Regresyon Analizine İlişkin Bulgular

\begin{tabular}{|c|c|c|c|c|c|c|c|c|}
\hline \multirow[t]{2}{*}{ Bağımsız Değişkenler } & \multicolumn{2}{|c|}{ 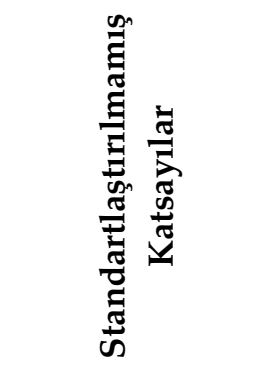 } & \multirow{2}{*}{ 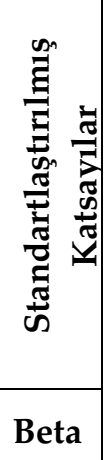 } & \multirow[t]{2}{*}{$\mathbf{R}^{2}$} & \multirow[t]{2}{*}{ 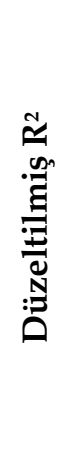 } & \multirow[t]{2}{*}{$\begin{array}{l}\vec{D} \\
\stackrel{D}{\mathscr{D}}\end{array}$} & \multirow[t]{2}{*}{ 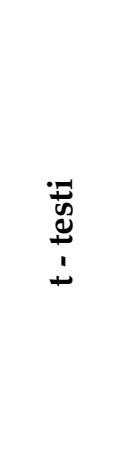 } & \multirow[t]{2}{*}{ 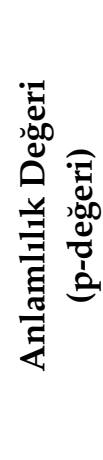 } \\
\hline & B & Std. Hata & & & & & & \\
\hline Sabit & 841 & 155 & & ,567 & ,560 & 85,070 & & ,000 \\
\hline Sosyo Kültürel & , 145 & ,031 & 181 & & & & 4,735 & ,000 \\
\hline $\begin{array}{l}\text { Kalabalık ve } \\
\text { Yoğunluk }\end{array}$ & ,345 & 034 & 395 & & & & 10,048 & ,000 \\
\hline Çevresel & ,087 & ,034 & 106 & & & & 2,568 & ,011 \\
\hline Hizmetler &,- 058 & ,028 & 090 & & & & $-2,035$ & ,043 \\
\hline Vergiler & ,302 & ,028 & ,410 & & & & 10,608 & ,000 \\
\hline $\begin{array}{l}\text { Yöre Sakinlerinin } \\
\text { Tutumu }\end{array}$ &,- 016 & ,028 & $\begin{array}{r}- \\
, 024\end{array}$ & & & &,- 549 &, 583 \\
\hline $\begin{array}{l}\text { Çoklu Bağlantı İstatistikl } \\
\text { Durbin-Watson (DW) Testi: } \\
\text { En küçük - en büyük VIF: 1, } \\
\text { En küçük-en büyük Tolerar } \\
\text { Bağımlı Değişken: Ekonomi }\end{array}$ & $\begin{array}{l}748(1, \\
0-1,7 \\
: 0,566\end{array}$ & $\begin{array}{l}-2,5) \\
0,763\end{array}$ & & & & & & \\
\hline
\end{tabular}

Bulgulardan anlaşılacağı gibi, bağımsız değişkenlerden "Sosyo Kültürel", "Kalabalık ve Yoğunluk", "Çevresel", "Hizmetler" ve "Vergiler" yöre sakinlerin ekonomik getirisine etki ederken, "Yöre Sakinlerinin Tutumu" değişkeni, anlamlı bir etkiye sahip değildir. Oluşturulan modelde, yöre sakinlerinin ekonomik getirisi ile Sosyo Kültürel değişken arasında \%18,1, Kalabalık ve Yoğunluk değişkeni arasında \%39,5, Çevresel değişken arasında \%10,6, Hizmetler değişkeni arasında \%9 ve Vergiler değişkeni arasında \%41 oranında kısmi korelasyon olduğu görülmektedir. Buna göre, İsfanbul Tema Park çevresinde yaşayan yerel halkın sosyo kültürel düzeyindeki bir birimlik artış, yöre halkının ekonomik düzeyinde 0,181 birimlik bir artışa; kalabalık ve yoğunlukta yaşanacak bir birimlik artış, yöre halkının ekonomik düzeyinde 0,395 birimlik bir artışa; çevresel koşullarda oluşacak bir birimlik artış, yöre halkının ekonomik düzeyinde 0,106 birimlik bir artışa; hizmetlerde yaşanacak bir birimlik artış, yöre halkının ekonomik düzeyinde 0,090 birimlik bir düşüşe; vergiler düzeyinde oluşacak bir birimlik artış ise yöre halkının ekonomik düzeyinde 0,410 birimlik bir artışa yol açmaktadır.

\section{SONUÇ}

İsfanbul Tema Parkın ekonomik etkisini belirlemeyi amaçlayan bu çalışma, nicel araştırma yaklaşımı ile hazırlanmıştır. Bu kapsamda veri elde etmek için Ap ve Crompton (1998) tarafından 
geliştirilen turizm etki ölçeği kullanılmıştır. Çalışmada turizm etki ölçeğinin orijinal boyutlarına sadık kalınarak 7 boyut (sosyo - kültürel, ekonomik, kalabalık ve yoğunluk, çevresel, hizmetler, vergiler, yöre sakinlerinin tutumu) kapsamında incelenmiştir. İlk önce araştırmaya katılan katılımcıların demografik özelliklerine yer verilmiştir. Daha sonra Turizm etki ölçeğinin boyutlarının (Sosyo Kültürel, Kalabalı ve Yoğunluk, Çevresel, Hizmetler, Vergiler, Yöre Sakinlerinin Tutumu), ekonomi üzerine etkisini belirleyen regresyon analizine yer verilmiştir.

Regresyon testi sonuçlarına göre, "Sosyo Kültürel(+)", "Kalabalık ve Yoğunluk(+)", “Çevresel(+)", "Hizmetler(-)" ve "Vergiler(+)" değişkenleri bölge sakinlerinin ekonomik getirisine etki ederken, "Yöre Sakinlerinin Tutumu" değişkeninin, bölge sakinlerinin ekonomik getirisi üzerinde anlamlı bir etkiye sahip olmadığı görülmektedir. Bu sonuçların bazıları literatürde yer alan çalışmalar ile desteklenmektedir. Örneğin; Arroyo (2007), tema parkların ekonomik etkilerinin yüksek olduğuna vurgu yapmıştır. Milman vd., (2010) tema parkların vergi gelirleri gibi birçok alanda destinasyonların sürdürülebilirliğine büyük katkı sağladığı sonucuna varmışlardır. Dolayısıyla yapılan bu çalışmada da vergilerin ekonomiyi pozitif yönde etkilediği bulgulanmıştır. Yerel yönetimlerin tema park projeleri ile hem yöre halkına hem de ülke ekonomisine önemli katkı yaratacağı görülmektedir.

Levochkina (2018) ise tema parkların bölgesel kalkınmada önemli olduğuna dikkat çekmiştir. Tüm bunların yanı sıra bu çalışma sonuçlarında da görüleceği üzere Sasaki vd. (1997), tema parkların hizmetler üzerinde olumsuz etkiye sahip olduğunu söylemektedirler. Bu sonuçtan yöre halkının tema parkların artması ile birlikte belediyenin vereceği hizmetlerde aksamalar olabileceği düşüncesini çıkarabiliriz. Tabi ki bu sonuç, bu durumun her zaman böyle olacağını göstermez. Eğer ki yerel yönetimler tema parkın kurulması ve yönetilmesi konusunda planlı ve programlı hareket eder ve yöre halkını bu konuda mağdur etmez ise hizmetlerin olumsuz olmasının aksine daha iyi hizmet kalitesine ulaşılması kaçınılmaz olacaktır. Dolayısıyla bölgesel gelişme ve destinasyonların sürdürülebilirliği açısından politika yapıcıların tema parkların rasyonel kurgulanıp ve yönetilmesine daha çok önem vermesi gerektiği söylenebilir.

Tema parkı şirketlerinin önemli Kurumsal Sosyal Sorumluluk faaliyetleri üstlendiği ve destinasyonların sürdürülebilirliğine katkıda bulunduğu açıktır (Milman vd., 2010). Dolayısıyla yerel yönetimler, Kurumsal Sosyal Sorumluluk faaliyetlerine daha fazla yatırım yapmaya devam etmekle kalmamalı, aynı zamanda birçok bölgedeki destinasyonların sürdürülebilirliğine katkısını göstermek için Kurumsal Sosyal Sorumluluk faaliyetlerini daha iyi tanıtmalıdırlar. Finansal bir bakış açısıyla yaklaşan Cornelis (2010)'in de söz ettiği gibi yeni cazibe merkezlerinin ekonomik etkilerinin kapsamı ve süresi hakkında açık ve net bilgiler, sorumlu ve hesap verebilir bir yatırım politikasının gerçekleştirilmesinin anahtarıdır. Bu çalışmanın sonuçlarından da anlaşılacağı üzere tema parkların ekonomik etkileri oldukça önem arz etmektedir. Dolayısıyla politika yapıcıların dikkatli ve planlı bir politika izleyerek tema parkların gelişimine destek vermesi hem bölgesel hem de ulusal ekonomi açısından önem arz etmektedir.

Araştırma alanı olarak sadece İsfanbul Tema Park bölgesinin seçilmesi araştırma kısıtlarını göstermektedir. Zaman ve maliyet bakımından yapılan çalışma, araştırmaya katılan kişiler ile sınırlı kalmaktadır. Bu kısıtların yanı sıra araştırmanın yapıldığı zaman aralığı da araştırma kısıtları arasında yer almaktadır. Ayrıca yeni tema parkları geliştirmek veya mevcut tema parklarına yenilerini eklemek büyük sermaye yatırımları gerektirir. Bununla birlikte, bu tür kararlar vermeden önce, tema parklarının başarı ve başarısızlıklarının analizi yatırımcılar ve yerel hükümet yetkilileri için yararlı bilgiler sağlayabilir. Dolayısıyla araştırmacılar, yeni cazibe merkezleri olan tema parkların katılımı üzerindeki etkilerini belirlemek için ekonometrik modelleri kullanabilirler. 


\section{KAYNAKÇA}

Alpar, R. (2010). Uygulamalı İstatistik ve Geçerlik-Güvenirlik. Ankara: Detay Yayınclık.

Ap, J. and Crompton, J. L. (1998). Developing and Testing a Tourism Impact Scale. Journal of Travel Research, 37(2), 120-130. https://doi.org/10.1177/004728759803700203

Arroyo, J. A. (2007). Economic Impacts of Theme Park Development on the Host Areas Case Study of Port Aventura and The Region of Costa Daurada, Spain. MA European Tourism Management, Bournemouth University and Universite Savoie.

Arslan, M. Tema parkları, Plant Dergisi. (22 Eylül 2016).

Bae, H. Y., Moon, S., Jun, J. W., Kim, T. and Ju, I. (2018). The impact of consumers' attitudes toward a theme park: A focus n Disneyland in the Los Angeles Metropolitan Area, Sustainability. (10). 1-13.

Balcı, A. (2011). Sosyal Bilimlerde Araştırma: Yöntem, Teknik ve Ilkeler. Ankara: Pegem Akademi.

Bobat, A. Geçmişle gelece arasında tema parklar, Plant Dergisi. (20 Eylül 2016).

Braun, B. M. and Milman, A. (1991). Localization economies in the theme park industry. The Review of Regional Studies. Regional Science Association 20(3), 33-37.

Braun, M. (2000). The economic impact of theme parks on regions. Neurus.

Cengizkan, A. (2014). The economics impact of theme parks on regions. http://aocarastirmalari.arch.metu.edu.tr/files/2014/05/AOC_ARCH714_Loredana-Gal.pdf.

Clavé, S. A. (2007). The global theme park industry. In the Global Theme Park Industry. Cambridge: CABI

Cornelis, P. (2010). Impact of new attractions on theme park attendance. Worldwide Hospitality and Tourism Themes. 2(3), ss. 262-280.

Crossley, J. C., Jamieson, L. M. and Brayley, R. E. (2018). Introduction to commercial recreation and tourism: An entrepreneurial approach (7. basım). Urbana, IL: Sagamore-Venture Publishing LLC.

De Groote, P. (2011). Globalisation of commercial theme parks Case: the Walt Disney Company. APSTRACT: Applied Studies in Agribusiness and Commerce, 5(1033-2016-84139), 21-28.

Geissler, G. L. and Rucks, C. T. (2011). The overall theme park experience: A visitor satisfaction tracking study. Journal of Vacation Marketing, 17(2), 127-138.

George, D. and Mallery, M. (2010). SPSS for Windows Step by Step: A Simple Guide and Reference, 17.0 update (10a ed.) Boston: Pearson

Hair, J., Black, W., Babin, B. and Anderson, R. (2010). Multivariate Data Analysis: A Global Perspective. In Multivariate Data Analysis. Upper Saddle River, NJ: Prentice Hall.

https://tourismembassy.com/en/news/tourism-industry/impacts-of-amusement-parks-ontourism-

https://www.statista.com/topics/2805/amusement-and-theme-parks/

Karasar, N. (2005). Bilimsel Araştırma Yöntemi. Ankara: Nobel Yayınları.

Levochkina, N. A. (2018). Theme parks and their contribution to the development of territories. Earth and Environmental Science (204). 1-3. 
Lundberg, E. (2017). The importance of tourism impacts for different local resident groups: a case study of a Swedish seaside destination. Journal of Destination Marketing and Management, 6, 46-55.

Milman, A., Okumuş, F. and Dickson, D. (2010). The contribution of theme parks and attractions to the social and economic sustainability of destinations. Worldwide Hospitality and Tourism Themes, 2 (3). 338-345.

Nkemngu, Acha-Anyi P. (2015). Quality of life and tourism impacts: a community perspective. African Journal of Hospitality, Tourism and Leisure, 4 (1). 1-13.

Page, S. J. (2009). Tourism Management. Managing for Change (Third Edition). Oxford: Butterworth-Heinemann.

Raluca, D. C. and Gina, S. (2008). Theme park-the main concept of tourism industry development. Economy and Business Administration. 2. 635-640.

Sasaki, K., Harada, M. and Morino, S. (1997). Economic impacts of theme park development by input-output analysis: a process toward local industrialization of leisure services. Managing Leisure, 2. 29-38.

Sun, Lou- Hon and Uysal, M. (1994). The role of theme parks in tourism. Hospitality Review, 12 (1), 71-80.

Theme Index and Museum Index: The Global Attractions Attendance Report (2018), Themed Entertainment Association.

Ural, A. ve İbrahim, K. (2006). Bilimsel Araştırma Süreci ve SPSS İle Veri Analizi. Ankara: Detay Yayincilik.

Yazıcıŏ̆lu, Y. ve Erdoğan, S. (2007). SPSS uygulamalı bilimsel araştırma yöntemleri. Ankara: Detay Yayincilık.

Zhang, Y., Li, W. R., Su, Q. and Hu, X. (2017). Exploring a theme park's carrying capacity: A demand-side analysis. Tourism Management, 59, 564-578. 